\title{
Article \\ Estimation of Soiling Losses from an Experimental Photovoltaic
Plant Using Artificial Intelligence Techniques
}

Noelia Simal Pérez ${ }^{1}$, Joaquín Alonso-Montesinos ${ }^{1,2, *(1)}$ and Francisco Javier Batlles ${ }^{2}$

1 CIESOL, Joint Centre of the University of Almería-CIEMAT, 04120 Almería, Spain; noeesimal24@gmail.com

2 Department of Chemistry and Physics, University of Almería, 04120 Almería, Spain; fbatlles@ual.es

* Correspondence: joaquin.alonso@ual.es

check for

updates

Citation: Simal Pérez, N.;

Alonso-Montesinos, J.; Batlles, F.J.

Estimation of Soiling Losses from an

Experimental Photovoltaic Plant

Using Artificial Intelligence

Techniques. Appl. Sci. 2021, 11, 1516.

https://doi.org/10.3390/app11041516

Received: 11 November 2020

Accepted: 1 February 2021

Published: 8 February 2021

Publisher's Note: MDPI stays neutral with regard to jurisdictional claims in published maps and institutional affiliations.

Copyright: (c) 2021 by the authors. Licensee MDPI, Basel, Switzerland. This article is an open access article distributed under the terms and conditions of the Creative Commons Attribution (CC BY) license (https:// creativecommons.org/licenses/by/ $4.0 /)$.

\begin{abstract}
Fossil fuels and their use to generate energy have multiple disadvantages, with renewable energies being presented as an alternative to this situation. Among them is photovoltaic solar energy, which requires solar installations that are capable of producing energy in an optimal way. These installations will have specific characteristics according to their location and meteorological variables of the place, one of these factors being soiling. Soiling generates energy losses, diminishing the plant's performance, making it difficult to estimate the losses due to deposited soiling and to measure the amount of soiling if it is not done using very economically expensive devices, such as high-performance particle counters. In this work, these losses have been estimated with artificial intelligence techniques, using meteorological variables, commonly measured in a plant of these characteristics. The study consists of two tests, depending on whether or not the short circuit current (Isc) has been included, obtaining a maximum normalized root mean square error (nRMSE) lower than $7 \%$, a correlation coefficient $(\mathrm{R})$ higher than 0.9 , as well as a practically zero normalized mean bias error (nMBE).
\end{abstract}

Keywords: soiling; photovoltaic plant; solar energy; PV plant maintenance; ANN; machine learning

\section{Introduction}

Of all the renewable energy sources, solar photovoltaic (PV) energy is considered one of the best options for generating clean energy [1,2]. This type of technology is free of the polluting emissions that cause the greenhouse effect [3]. On studying the energy demand worldwide and the possibility of supplying it with solar photovoltaic energy technology, one can say that it is feasible since about four million exajoules $\left(E J=10^{18} \mathrm{~J}\right)$ of solar energy is received each year, of which, $5 \times 10^{4} \mathrm{EJ}$ can be used $\left(1.25 \times 10^{-20} \%\right)$. Furthermore, much of the landmass is capable of harnessing it. Consequently, if one has the facilities and the appropriate form of production, this objective could be achieved, even if, at the moment, its contribution to worldwide supply is very low [4].

In Spain, the southern zone is in one of the areas receiving the most solar radiation. Nonetheless, the country's energy policy has not encouraged the development and application of solar technology. The economic and socials situation experienced in previous years has meant that the necessary security for promoting this type of technology has been absent [5]. However, this is changing, and not only in Spain-solar energy generated by photovoltaic plants is being promoted more and more as an energy source, with the number of plants increasing globally [6]. These installations greatly improve issues related to the economy and the environment [7].

Large-scale photovoltaic plants are often sited in desert locations to maximize potential energy production [8]. Once the location has been determined, there are many factors that influence the plant's production-the type of technology used, the orientation of the panels and the tilt angles, etc., are some of the variables that need to be considered during the pre-installation work. To this end, there are numerous studies that show 
the appropriate configurations, depending on the location and/or weather conditions. In this regard, it is worth mentioning the direct relationship between the atmospheric variables and plant optimization-irradiance, ambient temperature, relative humidity, and pressure, etc., are variables that must be taken into account when determining the best locations (within the same region of interest). Studies on this subject have shown that such variables are related to the place and circumstances where the plant is located $[9,10]$, as well as the possible presence (or not) of soiling, common in desert and other areas that may be in the path of intense soiling currents [11,12]. In general, dust is the most studied pollutant to analyze the performance of solar photovoltaic systems. Dust soiling is a factor that has appeared and has been studied as photovoltaic solar systems have been built. Specifically, this phenomenon appears by covering the photovoltaic panels with a layer of dirt (causing deposition on the panels [13]), reducing the performance, and, consequently, the electrical production of each photovoltaic panel $[14,15]$. Therefore, soiling becomes a fundamental issue in terms of optimization [16] and, thus, on photovoltaic plant production. The accumulation of soiling and dirt makes it more difficult for radiation to reach the panels, thus reducing performance $[17,18]$. Desert climates are areas of the planet where these phenomena occur most, with particles being able to travel far from their place of origin [19]. As for the cycles of these currents, one could say that in the east of the European continent, they occur at the end of winters and in the west from June to September [20,21]. However, there are other phenomena that can affect the production of a solar photovoltaic system. The location of the system is fundamental since it can be in the vicinity of an industry with waste in the atmosphere that can deposit on the panels, as is the case of mining in Chile [22], where the contaminants emitted into the atmosphere are usually deposited on the roof of the photovoltaic panels of the adjacent solar plants. Pollen is usually another phenomenon that is transported in the environment and, in rural areas, can end up precipitating on the field of photovoltaic panels whenever they are in nearby areas. In addition, dirt due to animal droppings are another cause of fouling and the need for programmed maintenance.

The studies looking at this topic have presented multiple conclusions, each related to the conditions occurring at the place and time that each study was carried out [16]. They have studied the importance of the soiling molecule size as well as the optimal inclination angle of the photovoltaic panels. However, the most important and fundamental issue of the work is the relationship between the short-circuit current and soiling accumulation $[23,24]$ - a very important indicator to consider if the losses caused by fouling are to be predicted [23]. By comparing two photovoltaic panels, with and without maintenance, it can be seen how the value of the short circuit current is greater when maintenance is carried out on the panel. The more radiation reaches the panels, the greater the difference between the two currents [23]. It has been shown that soiling has a very representative effect on the short circuit current, decreasing its value considerably. In the IV curves, this effect can be seen, comparing a curve of a panel with maintenance and another without maintenance. The current is the most affected because it has a linear relationship with the radiation, while the voltage hardly notices any difference. When receiving less radiation, this value will decrease.

Therefore, the soiling significantly affects the degradation of the panels, affecting the cost of the plant and avoiding the expected profits. Photovoltaic plants are exposed to episodes of soiling, contamination, or meteorological phenomena that reduce performance (past African) (simulation). Knowing how the accumulation of soiling affects the installation is fundamental when establishing correct maintenance of it $[25,26]$. For a correct cleaning, besides the moment in which it is done, it is fundamental how to carry out this task. If manual cleaning is chosen, it is necessary to know that such cleaning can damage the panels, besides allowing the permanence of small particles. The use of detergents presents multiple disadvantages for the environment and the panel itself, in view of the danger of corrosion. All of this leads to a more automatic process to avoid situations of this type [17]. Therefore, it is necessary to have information on the state of soiling of a 
plant, to determine the ideal time to clean the photovoltaic panels, thus saving natural or economic resources. Therefore, if a maintenance plan for the panels is to be effective, it is essential to be able to know how soiling affects the installation. This maintenance must be optimal, and for this, it is necessary to know the right time to perform it [27].

Given the importance of soiling on performance, this study has estimated the losses due to dust soiling in a photovoltaic plant, using meteorological variables as well as those specific to the installation, such as the short-circuit current (Isc), the module temperature (Tpanel), global irradiation (Iglo), relative humidity (RH), ambient temperature (Tamb), atmospheric pressure $(\mathrm{P})$, and solar altitude $(\alpha)$. These were then combined with artificial neural networks. In this work, it has been modeled the soiling losses incurred by an experimental pilot plant installed at the Solar Energy Research Center (CIESOL). It has been mainly compared measurements from two panels, one receiving maintenance and the other not. Subsequently, artificial intelligence techniques, such as artificial neural networks, were employed to estimate soiling losses from parameters commonly measured in any photovoltaic plant.

\section{Materials and Methods}

\subsection{Photovoltaic System}

This study was carried out in an experimental photovoltaic plant located in the Solar Energy Research Center (CIESOL) at the University of Almería (Spain), where numerous studies are being conducted with a view to integrating solar energy into different areas. The emplacement is located in southeast Spain, with a Mediterranean climate $\left(36.8^{\circ} \mathrm{N}\right.$, $2.4^{\circ} \mathrm{W}$, at sea level). The photovoltaic system began operating on 24 July 2019. Figure 1 shows a picture of the photovoltaic plant.

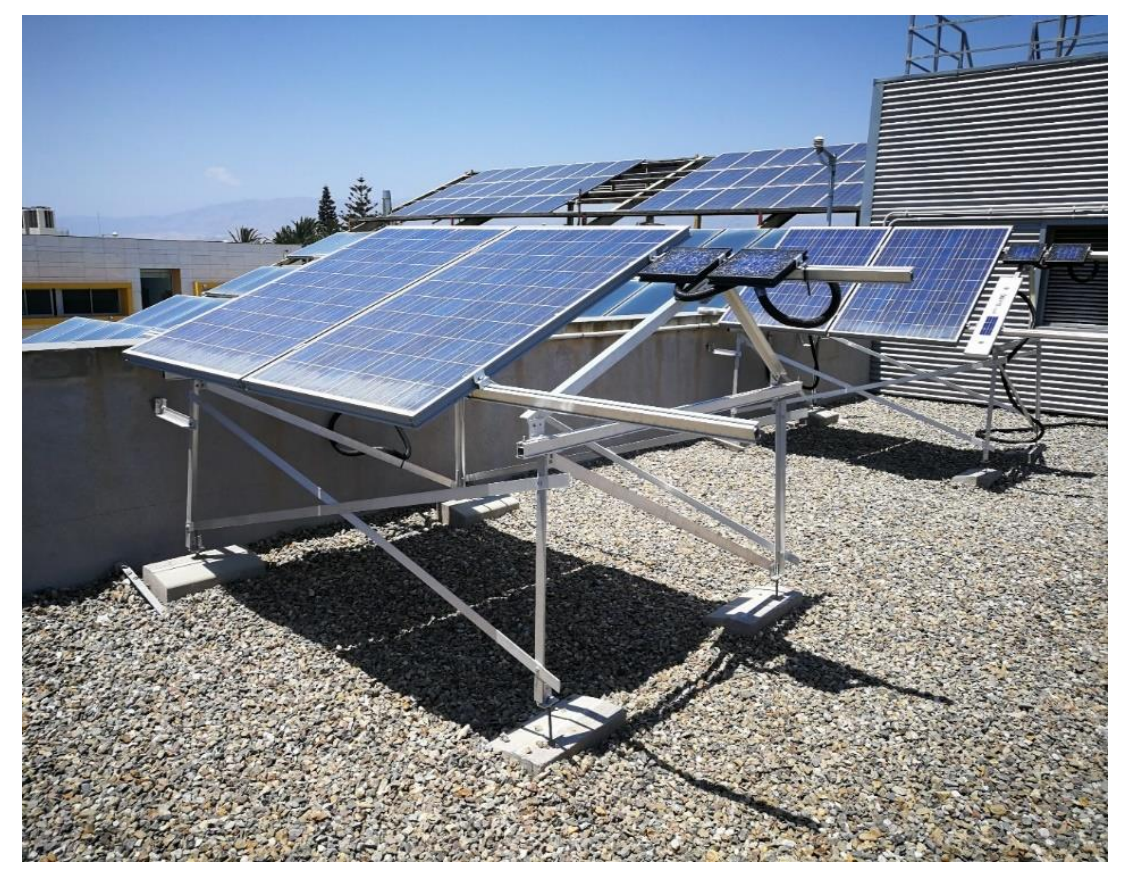

Figure 1. Experimental photovoltaic plant.

The image shows the photovoltaic panels along with the other components and sensors with which the installation is equipped. The plant has four south-oriented photovoltaic panels (ATERSA model A222-P), two on the north side of the roof and two on the south side. For the work, only the two south-side panels were used. In this sense, only two panels were compared because the dust response was similar in nearby locations. The limitation that it could have was that they have only been analyzed at an inclination $\left(22^{\circ}\right)$ to make them coincide with the inclination of a $10 \mathrm{kWp}$ photovoltaic plant precisely in a higher plant. After attending to different sensitivity analyses of variations between panels, 
it was obtained that the Isc is one of the variables most affected by dust; therefore, having only two panels was enough to quantify how the Isc value could vary over time when one panel had frequent maintenance and the other, no maintenance at all. As said, one of these panels was periodically cleaned while the other was not. To perform maintenance and cleaning of panels, the panel with maintenance was cleaned with water and a soft cloth. Subsequently, they were dried with paper, and this was done daily. This allowed us to compare the short-circuit current measurements obtained from each.

Two Pt100 temperature sensors were positioned on each panel, providing us with the panel temperature. One of them was located on the top rear part of the photovoltaic module, whilst the other was located in the bottom rear part. When working with this data, the average temperature of both sensors is calculated to give a representative value. This was done exclusively on the unmaintained panel since the temperature sensor located in the southern area of the maintenance panel provided erroneous data (a sensor defect) and, therefore, was not used. On the back of the panels, there were also shunts (Shunt $15 \mathrm{~A} / 150 \mathrm{mV}$ KL.0.5 KAYNOS), from which the short-circuit current was obtained as a voltage measurement (in $\mathrm{mV}$ ). Located to the right of the panels on the metal support structure are the calibrated cells that provide global irradiance data on the array plane (at the same inclination as the panels). One of the cells was maintained in an optimally clean condition, while the other was not maintained at all. Finally, the installation had a sensor that measures both the ambient temperature and the relative humidity, as well as a barometer that measured the atmospheric pressure. Table 1 shows the information concerning the sensors and measuring ranges, thus presenting a metrological analysis of the sensors.

Table 1. Metrological analysis of sensors.

\begin{tabular}{|c|c|c|c|c|c|c|}
\hline Measure & Sensor & Initial Measurement Unit & Conversion Factor & Unit & $\Delta$ Measure & Range \\
\hline Short-circuit current (Isc) & $\begin{array}{c}\text { Shunt } 15 \mathrm{~A} / 150 \mathrm{mV} \\
\text { KL.0.5 KAYNOS }\end{array}$ & $\mathrm{mV}$ & $100 \mathrm{mV}$ & A & $\pm 1 \times 10^{-2}(\mathrm{~A})$ & $(0,15)(\mathrm{A})$ \\
\hline Panel temperature & Pt 100 RS PRO & ${ }^{\circ} \mathrm{C}$ & - & ${ }^{\circ} \mathrm{C}$ & $\pm 1 \times 10^{-4}\left({ }^{\circ} \mathrm{C}\right)$ & $(-50,150)\left({ }^{\circ} \mathrm{C}\right)$ \\
\hline Tilted global irradiance & $\begin{array}{c}65 \mathrm{mV} \text { Compensated } \\
\text { calibrated cell (ATERSA) }\end{array}$ & $\mathrm{mV}$ & $15.385 \mathrm{mV}$ & $\mathrm{Wm}^{-2}$ & $\pm 1 \times 10^{-6}\left(\mathrm{Wm}^{-2}\right)$ & $(0,1000)\left(\mathrm{Wm}^{-2}\right)$ \\
\hline Ambient temperature & HMP 60 Vaisala & $\mathrm{mV}$ & $-40+50 \mathrm{mV}$ & ${ }^{\circ} \mathrm{C}$ & $\pm 1 \times 10^{-7}\left({ }^{\circ} \mathrm{C}\right)$ & $(-40,60)\left({ }^{\circ} \mathrm{C}\right)$ \\
\hline Relative humidity & HMP 60 Vaisala & $\mathrm{mV}$ & $50 \mathrm{mV}$ & $\%$ & $\pm 1 \times 10^{-7}(\%)$ & $(0,100)(\%)$ \\
\hline Barometric pressure & PTB 110 Vaisala & $\mathrm{mV}$ & $500+0.24 \mathrm{mV}$ & $\mathrm{hPa}$ & $\pm 1 \times 10^{-5}(\mathrm{hPa})$ & $(500,1100)(\mathrm{hPa})$ \\
\hline
\end{tabular}

\subsection{Data Processing}

Thanks to the different sensors that the plant had, its behavior was monitored, recording values every minute. The sensors were connected to a data acquisition system, a datalogger, which in turn was connected to a computer server that stored the records. The data used were gathered from 24 July 2019 to 14 February 2020, a period in which the southern panels had a 22-degree inclination. The main objective was to create a solid database to provide sufficient valid measurements to accurately and optimally model the variable to be estimated. To do this, first, the night-time data was eliminated thanks to the solar altitude angle (formed by the straight line from the earth's surface to the sun), its value being zero at the beginning and end of the day. In meteorological studies, this parameter is of great importance and so is stored along with the other variables. After eliminating these night-time values, any erroneous values caused by current failure, data acquisition errors, and damage to sensors, etc. were filtered out.

\subsection{Measurement Calibration for Standardization}

Leaving aside the filtering, the next phase consisted of normalizing the irradiance measurements on the array plane and the short-circuit current. This was necessary because the panels, despite being equal, did not give exactly the same measurements. If both measurements were identical, the following step would not have been necessary. To correct 
this error, both the calibrated cell and the short-circuit current from the unmaintained panel were multiplied by two correction factors. These factors were calculated from reference measurements taken at midday on the first optimal day of plant operation under standard conditions. With these data, it was known, minute by minute, what loss originated from soiling accumulation on the unmaintained photovoltaic panel since the two panels were now calibrated; therefore, the final difference between the values from the two panels would be due only to soiling. In this work, the influence of soiling was very significant on the short-circuit current. To quantify the instantaneous losses as a percentage, the mathematical expression shown in Equation (1) was used [28].

$$
\text { Losses }(\%)=100 \times \frac{\frac{\mathrm{Isc}_{\text {maintained panel }}}{\mathrm{Isc}_{\text {maintained panel }} \mathrm{Ref}}-\frac{\mathrm{Isc}_{\text {maintenance-free panel }}}{\mathrm{Isc}_{\text {maintenance-free panel }} \mathrm{Ref}}}{\mathrm{Isc}_{\text {maintained panel }}}
$$

Once the standardization had been carried out, both panels should have always given the same measurements unless one of them was affected by an issue that does not occur in the other, as in whether they were maintained or not. If standardization was guaranteed, the only difference possible was that caused by soiling; therefore, this was the value used to model the equation. The soiling factor that could be extrapolated to a real plant would be that of the panel without maintenance, as panels can go years without receiving such maintenance.

\subsection{Correlation between the Variables and Soiling Losses}

In this study, it was fundamental to understand the relationships between the variables in order to study their dependencies. For this purpose, the Pearson correlation coefficient was used, which is widely used, especially in studies modeling atmospheric and/or meteorological variables. With the idea of estimating the result of a model in a simple and abbreviated way, this coefficient allowed us to know the parameters that most influence the output variable [29]. The coefficient values range from -1 to 1 , with the correlation being positive when it is greater than zero and negative when it is less. If the values coincide with the previous figures, the correlation is perfect, being nonlinear when the null value is obtained.

In this section, the correlation was studied between the meteorological and installationspecific variables and losses caused by soiling. Knowing this is of fundamental importance. Having measurements that are perfectly standardized and calibrated means that any possible differences between the panels (with or without maintenance) were the result of a soiling layer (or film) on the unmaintained panel-this will be the loss that occurs due to soiling on the photovoltaic panel. Figure 2 shows the dispersion diagrams of each variable against the instantaneous soiling losses, while Table 2 shows the correlations between the instantaneous soiling losses and the different variables.

Table 2. Correlation coefficient of variables against instantaneous soiling losses.

\begin{tabular}{ccccccc}
\hline Tpanel $\left({ }^{\circ} \mathbf{C}\right)$ & Isc (A) & $\operatorname{Iglo}\left(\mathbf{W m}^{-2}\right)$ & $\mathbf{R H}(\%)$ & $\operatorname{Tamb}\left({ }^{\circ} \mathbf{C}\right)$ & $\mathbf{P}(\mathbf{h P a})$ & $\alpha\left({ }^{\circ}\right)$ \\
\hline 0.17 & 0.03 & 0.06 & -0.07 & 0.47 & -0.20 & 0.08 \\
\hline
\end{tabular}



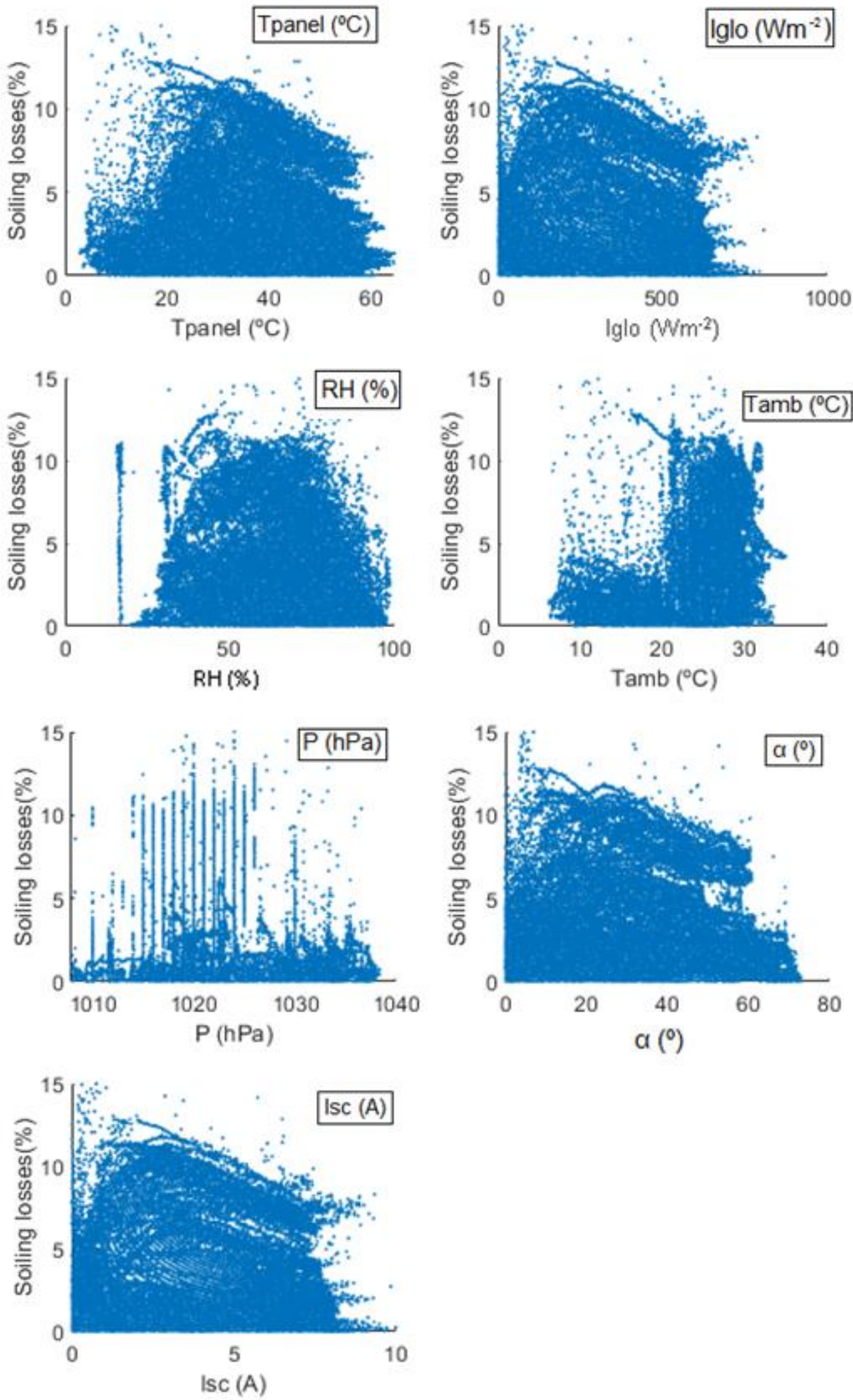

Figure 2. Scatter plots of variables against instantaneous soiling losses. Tpanel: module temperature; Iglo: global irradiation; RH: relative humidity; Tamb: ambient temperature; P: atmospheric pressure; $\alpha$ : solar altitude. 
No single variable was highlighted as having a strong correlation with soiling losses because it is complex to model them. The variables with the highest correlation were ambient temperature, pressure, and panel temperature, but none stood out; indeed, they indicated rather moderate relationships. The rest of the values were very close to zero, so there would be no correlation with soiling losses in any of these cases. Relative humidity and pressure had negative values, unlike the others, which were positively correlated. The graphs support these parameters, as only the ambient temperature shows some correlation with the losses. Therefore, there was a circumstance in which there was no linearity between the input and output variables that would be obtained in a future model.

\subsection{Model Development}

In terms of common tools for estimating a variable, artificial neural networks (ANN) occupy an important place. They are part of "Machine Learning" technology and have a remarkable capacity for learning patterns, making it possible to estimate an output variable autonomously. As for the network structure, first of all, there is the input layer, where the records are introduced for each of the variables to be considered as part of the input parameter. Then there is the hidden layer, where the interconnections between the variables are made, allowing conclusions to be drawn and the variable to be estimated in the output layer. The creation of the networks is comprised of two stages-training and validation. In the training stage, the input variables and the real output variable are introduced so that the network learns to estimate these values according to the inputs available. To check if it is effective and capable of predicting the correct values, other different input data are introduced in the validation phase, for which the network has to calculate the output values [30].

In this study, soiling losses of a photovoltaic panel are modeled using two possible alternatives: the first did not contemplate the introduction of the short circuit current from the unmaintained panel as the red neuronal input (model 1), whereas the second did (model 2), the aim being to determine the best solution and thus provide a more accurate model.

With this information, the final objective is to construct an optimal artificial neural network with the least number of input variables and the minimum execution time, where the toolbox 'Neural Net Fitting' from MATLAB [31] and the Levenberg-Marquardt algorithm were used to create the ANN functions. In order to carry out correct modeling of the recorded data, $80 \%$ of the records have been assigned to the training phase and $20 \%$ to the validation phase, that is to say, of the total data, 101,633, 81,306 have been assigned for training and 20,327 for validation. Within the training, MATLAB handles with certain inflexibility the training and validation patterns. Although, of the $80 \%$ of the data used for training, MATLAB requires using at least $5 \%$ for testing and $5 \%$ for validation (both internal to the training). In this case, that configuration was determined, where $90 \%$ (of the $80 \%$ of data for training) has been used for training and the rest for internal validations. It should be noted that always $20 \%$ of the data was independent to make a validation of the models that will have nothing to do with the training data set.

In the hidden layer, there were a series of neurons, and each neuron had an exit and several entrances. The output of all the neurons in one layer are the inputs of each of the neurons in the next layer, so each neuron calculates its output on the basis of all these inputs. The function that relates the output of the neuron to the input is defined by the weights that each neuron has with each input. These weights are defined during training.

To achieve this, the modeling process began by creating a network with the maximum number of inputs using all the available variables. Subsequently, each variable was removed, one by one, to observe the errors made by the network in the training, test and validation phases, eliminating only the variable where the error is lowest. This operation is repeated until an optimal set was found to model the variable in question. The statistical variables help to decide these situations. When the best network is selected, it will have to be adjusted according to the number of hidden neurons; this serves as an optimization 
task for the resulting network. With more neurons in the hidden layer, the interconnections between the variables are increased, although this does not always make the network more optimal as the duration is usually quite long. Therefore, it is possible that better results are obtained with a network with fewer interconnections. The selection criteria have been used to obtain a value of MSE as close to zero as possible, as well as a value of $\mathrm{R}$ as close to one, trying to have the network have as few iterations as possible.

\subsubsection{ANN Model 1}

Firstly, the soiling losses were modeled in the absence of the short-circuit current of the unmaintained panel. Figure 3 shows the structure of the initial network.

\section{Inputs layer}

Hidden layer

Output layer

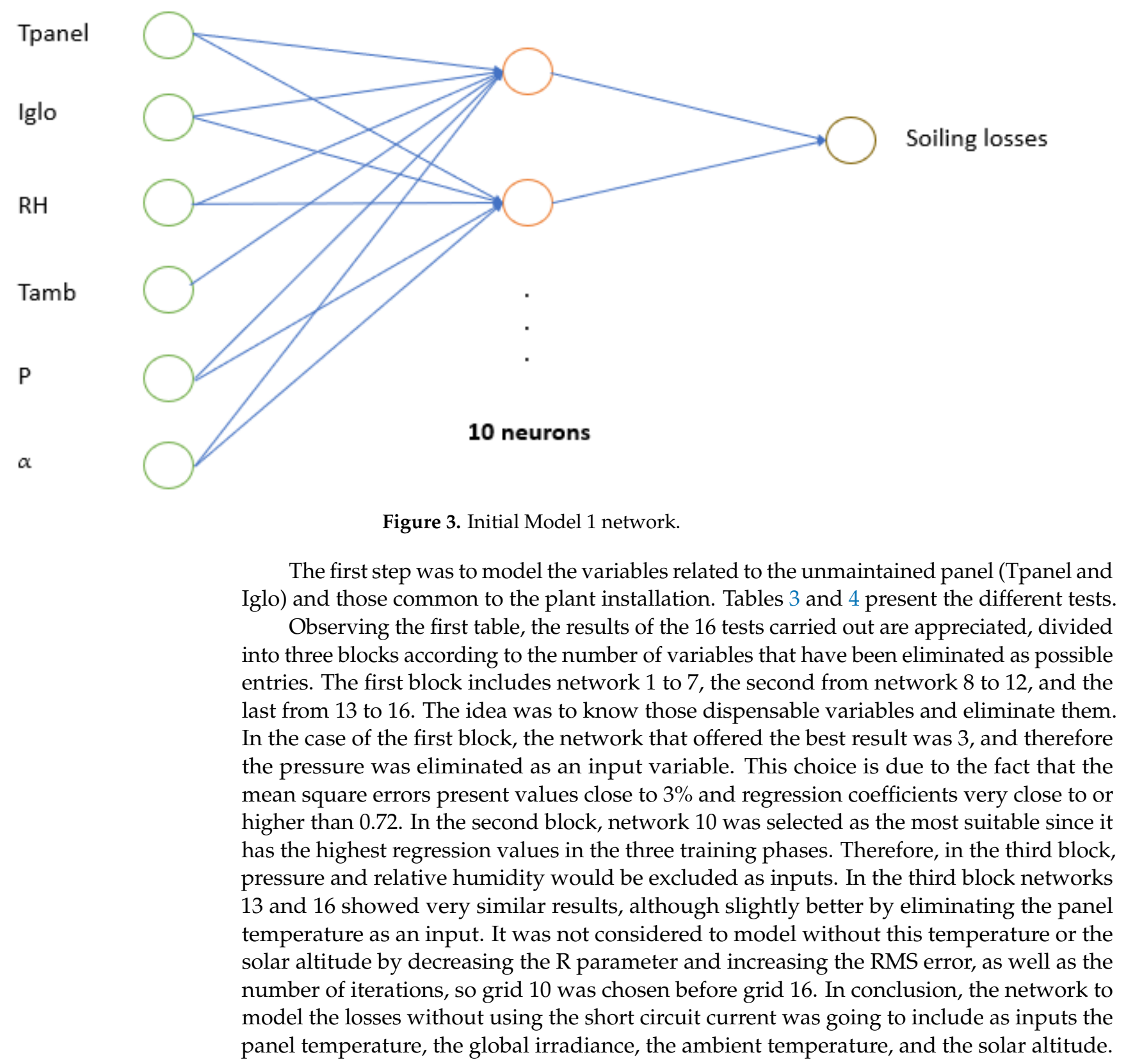


Table 3. Artificial neural network (ANN) Model 1 results with 10 neurons. NET: network; MSE: Mean square error.

\begin{tabular}{|c|c|c|c|c|c|c|c|c|c|c|c|c|c|c|}
\hline \multirow[t]{2}{*}{ NET } & \multicolumn{5}{|c|}{ INPUTS } & \multicolumn{3}{|c|}{ TRAINING } & \multicolumn{2}{|c|}{ VALIDATION } & \multicolumn{2}{|c|}{ TESTING } & \multirow[b]{2}{*}{ Duration } & \multirow[b]{2}{*}{ Iterations } \\
\hline & Tpanel & Iglo & RH & Tamb & $\mathbf{P}$ & $\alpha$ & MSE & $\mathbf{R}$ & MSE & $\mathbf{R}$ & MSE & $\mathbf{R}$ & & \\
\hline 1 & $x$ & $x$ & $x$ & $x$ & $x$ & $x$ & 2.86 & 0.75 & 2.96 & 0.74 & 2.79 & 0.75 & 0:00:12 & 173 \\
\hline 2 & $x$ & $x$ & $x$ & $x$ & $x$ & & 3.29 & 0.7 & 3.37 & 0.69 & 3.19 & 0.71 & 0:00:05 & 85 \\
\hline 3 & $\mathbf{x}$ & $x$ & $x$ & $x$ & & $\mathbf{x}$ & 3.03 & 0.73 & 3.14 & 0.73 & 3.09 & 0.72 & 0:00:06 & 98 \\
\hline 4 & $x$ & $x$ & $x$ & & $x$ & $x$ & 4.07 & 0.61 & 3.88 & 0.61 & 4.24 & 0.62 & 0:00:07 & 117 \\
\hline 5 & $x$ & $x$ & & $x$ & $x$ & $x$ & 3.12 & 0.72 & 2.97 & 0.72 & 3.04 & 0.73 & 0:00:02 & 40 \\
\hline 6 & $x$ & & $x$ & $x$ & $x$ & $x$ & 3.47 & 0.68 & 3.46 & 0.69 & 3.35 & 0.69 & 0:00:06 & 106 \\
\hline 7 & & $x$ & $x$ & $x$ & $x$ & $x$ & 3.05 & 0.73 & 3.04 & 0.74 & 3.3 & 0.71 & 0:00:13 & 204 \\
\hline 8 & $x$ & $x$ & $x$ & $x$ & & & 3.37 & 0.69 & 3.34 & 0.69 & 3.25 & 0.7 & 0:00:06 & 103 \\
\hline 9 & $x$ & $x$ & $x$ & & & $x$ & 4.37 & 0.57 & 4.22 & 0.57 & 4.51 & 0.56 & 0:00:03 & 47 \\
\hline 10 & $\mathbf{x}$ & $x$ & & $x$ & & $\mathbf{x}$ & 3.19 & 0.71 & 3.17 & 0.71 & 3.23 & 0.71 & 0:00:04 & 65 \\
\hline 11 & $x$ & & $x$ & $x$ & & $x$ & 3.67 & 0.66 & 3.62 & 0.65 & 3.81 & 0.65 & 0:00:05 & 83 \\
\hline 12 & & $x$ & $x$ & $x$ & & $x$ & 3.2 & 0.71 & 3.31 & 0.7 & 3.17 & 0.7 & 0:00:02 & 39 \\
\hline 13 & $x$ & $x$ & & $x$ & & & 3.58 & 0.67 & 3.51 & 0.67 & 3.44 & 0.67 & 0:00:06 & 117 \\
\hline 14 & $x$ & $x$ & & & & $x$ & 4.39 & 0.57 & 4.26 & 0.57 & 4.33 & 0.57 & 0:00:10 & 179 \\
\hline 15 & $x$ & & & $x$ & & $x$ & 3.94 & 0.63 & 3.86 & 0.63 & 3.77 & 0.64 & 0:00:02 & 45 \\
\hline 16 & & $\mathbf{x}$ & & $x$ & & $\mathbf{x}$ & 3.47 & 0.68 & 3.65 & 0.68 & 3.61 & 0.68 & 0:00:11 & 216 \\
\hline
\end{tabular}

Table 4. ANN Model 1 results with more than 10 neurons.

\begin{tabular}{|c|c|c|c|c|c|c|c|c|c|c|c|c|c|c|}
\hline \multirow[t]{2}{*}{ NET } & \multicolumn{4}{|c|}{ INPUTS } & \multicolumn{4}{|c|}{ TRAINING } & \multicolumn{2}{|c|}{ VALIDATION } & \multicolumn{2}{|c|}{ TESTING } & \multirow[b]{2}{*}{ Duration } & \multirow[b]{2}{*}{ Iterations } \\
\hline & Tpanel & Iglo & RH & Tamb & $\mathbf{P}$ & $\alpha$ & MSE & $\mathbf{R}$ & MSE & $\mathbf{R}$ & MSE & $\mathbf{R}$ & & \\
\hline 10 & $x$ & $x$ & & $x$ & & $x$ & 3.19 & 0.71 & 3.17 & 0.71 & 3.23 & 0.71 & 0:00:04 & 65 \\
\hline 10_2 & $x$ & $x$ & & $x$ & & $x$ & 2.9 & 0.74 & 2.81 & 0.75 & 2.99 & 0.74 & $0: 00: 20$ & 177 \\
\hline $10 \_3$ & $x$ & $x$ & & $x$ & & $x$ & 2.82 & 0.75 & 2.91 & 0.76 & 2.87 & 0.76 & $0: 00: 13$ & 83 \\
\hline 10_4 & $x$ & $x$ & & $x$ & & $x$ & 2.73 & 0.76 & 2.63 & 0.76 & 2.76 & 0.77 & $0: 00: 29$ & 117 \\
\hline $10 \_5$ & $x$ & $\mathbf{x}$ & & $x$ & & $\mathbf{x}$ & 2.57 & 0.77 & 2.71 & 0.77 & 2.67 & 0.785 & 0:00:59 & 162 \\
\hline
\end{tabular}

Once the input variables to the network were chosen, other results were studied by altering the number of neurons in the hidden layer of the network. Tests were made from 10 to 50 neurons as shown in Table 4 (each row represents a new network with 10 neurons plus), being the last network the one selected. Although it had a longer duration, $R$ values of the order of 0.71 were obtained to work with values higher than 0.77 in the training process, so the network was more adjusted to the data.

Figure 4 shows the final network with the selected input variables.
Inputs layer
Hidden layer
Output layer

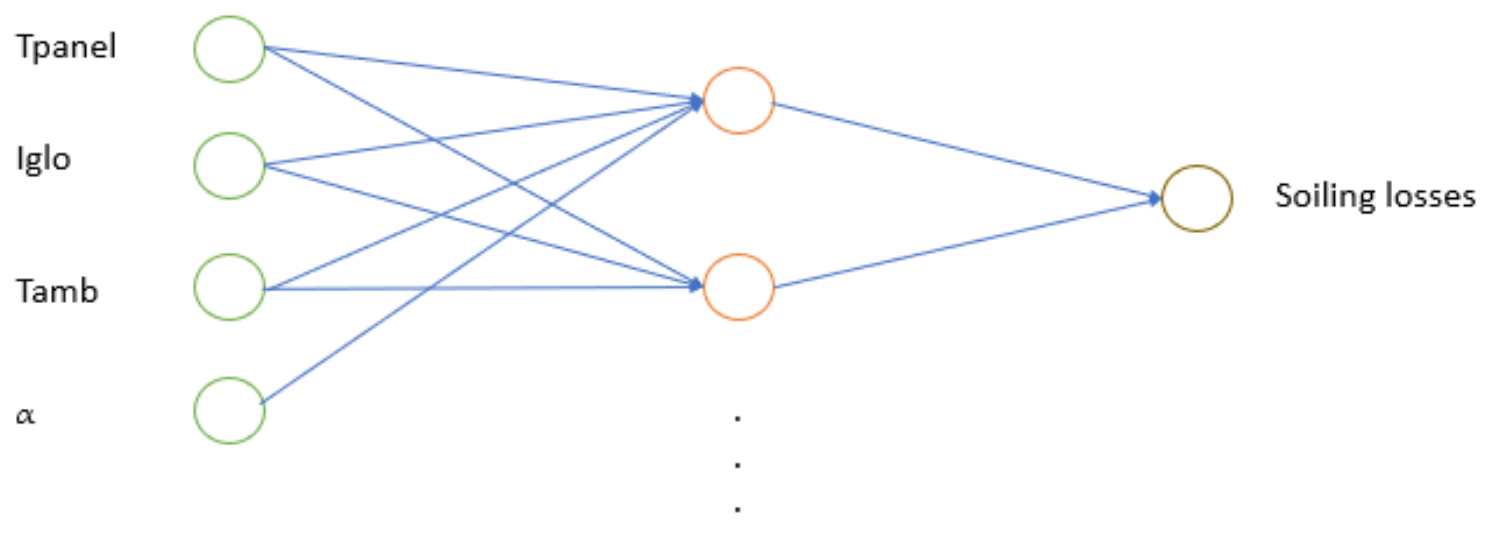

50 neurons

Figure 4. Final Model 1 network. 


\subsubsection{ANN Model 2}

Secondly, soiling losses were modeled by adding the short-circuit current of the unmaintained panel as an input. Figure 5 shows the structure of the initial network.

Inputs layer

Hidden layer

Output layer

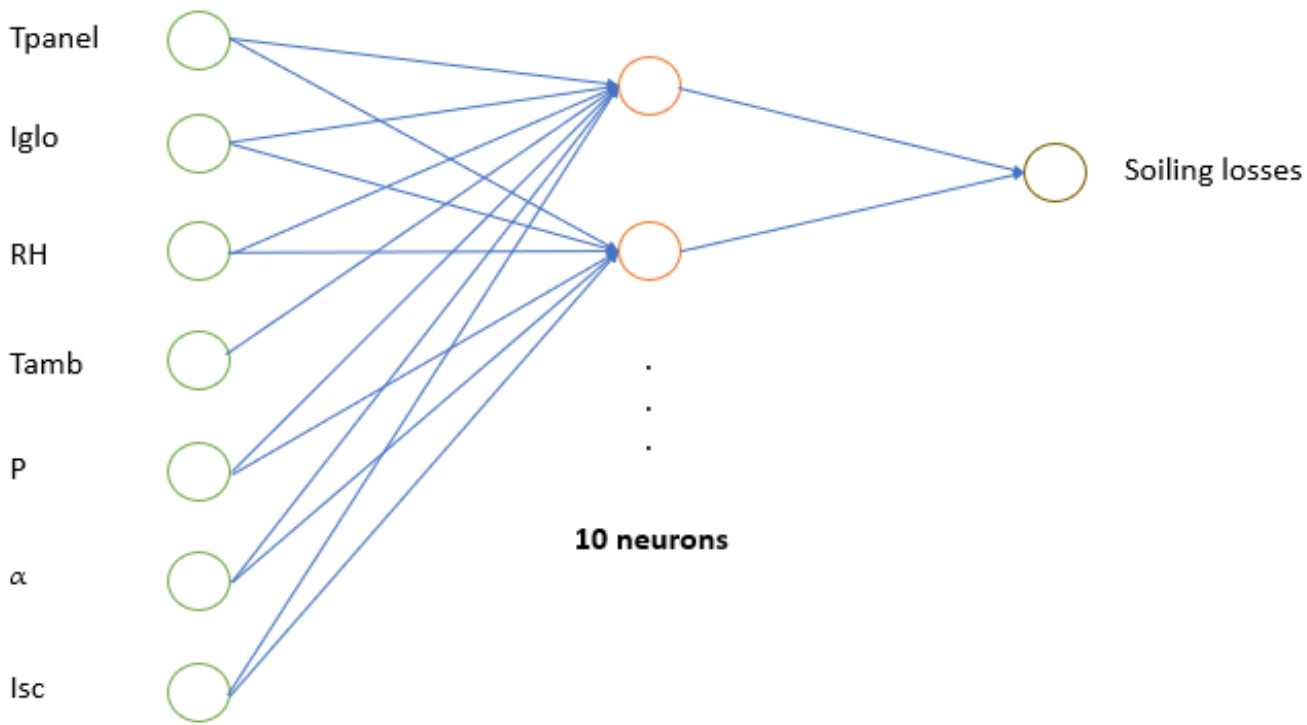

Figure 5. Initial Model 2 network.

The initial Model 2 variables are the same as in Model 1, apart from adding the shortcircuit current of the unmaintained panel as an extra input. Tables 5 and 6 present the different tests.

Table 5. ANN Model 2 results with 10 neurons.

\begin{tabular}{|c|c|c|c|c|c|c|c|c|c|c|c|c|c|c|c|}
\hline \multirow[t]{2}{*}{ NET } & \multicolumn{7}{|c|}{ INPUTS } & \multicolumn{2}{|c|}{ TRAINING } & \multicolumn{2}{|c|}{ VALIDATION } & \multicolumn{2}{|c|}{ TESTING } & \multirow[b]{2}{*}{ Duration } & \multirow[b]{2}{*}{ Iterations } \\
\hline & Tpanel & Iglo & RH & Tamb & $\mathbf{P}$ & $\alpha$ & Isc & MSE & $\mathbf{R}$ & MSE & $\mathbf{R}$ & MSE & $\mathbf{R}$ & & \\
\hline 1 & $x$ & $x$ & $x$ & $x$ & $\mathrm{x}$ & $x$ & $x$ & 1.12 & 0.91 & 1.12 & 0.91 & 1.15 & 0.9 & 0:00:05 & 69 \\
\hline 2 & $x$ & $x$ & $x$ & $x$ & $x$ & $x$ & & 2.68 & 0.76 & 2.57 & 0.77 & 2.7 & 0.76 & 0:00:08 & 118 \\
\hline 3 & $x$ & $\mathrm{x}$ & $\mathrm{x}$ & $x$ & $x$ & & $\mathrm{x}$ & 1.25 & 0.9 & 1.17 & 0.91 & 1.19 & 0.9 & 0:00:06 & 90 \\
\hline 4 & $x$ & $x$ & $x$ & $x$ & & $\mathbf{x}$ & $x$ & 1.09 & 0.91 & 1.04 & 0.92 & 1.05 & 0.91 & 0:00:24 & 331 \\
\hline 5 & $x$ & $x$ & $x$ & & $x$ & $x$ & $x$ & 1.35 & 0.89 & 1.38 & 0.89 & 1.37 & 0.89 & 0:00:04 & 61 \\
\hline 6 & $x$ & $x$ & & $x$ & $x$ & $x$ & $x$ & 1.17 & 0.9 & 1.13 & 0.91 & 1.09 & 0.91 & 0:00:13 & 189 \\
\hline 7 & $x$ & & $x$ & $x$ & $x$ & $\mathrm{x}$ & $x$ & 2.98 & 0.73 & 3.06 & 0.73 & 3.2 & 0.72 & 0:00:09 & 126 \\
\hline 8 & & $x$ & $x$ & $x$ & $x$ & $x$ & $x$ & 1.21 & 0.9 & 1.19 & 0.9 & 1.33 & 0.89 & 0:00:12 & 180 \\
\hline 9 & $x$ & $x$ & $x$ & $x$ & & $x$ & & 2.84 & 0.75 & 2.7 & 0.76 & 2.96 & 0.74 & 0:00:04 & 68 \\
\hline 10 & $x$ & $x$ & $x$ & $x$ & & & $\mathrm{x}$ & 1.24 & 0.9 & 1.19 & 0.91 & 1.34 & 0.89 & 0:00:06 & 105 \\
\hline 11 & $x$ & $x$ & $x$ & & & $\mathbf{x}$ & $x$ & 1.22 & 0.9 & 1.22 & 0.9 & 1.27 & 0.9 & 0:00:10 & 158 \\
\hline 12 & $\mathrm{x}$ & $\mathrm{x}$ & & $\mathrm{x}$ & & $x$ & $x$ & 1.19 & 0.9 & 1.24 & 0.9 & 1.35 & 0.89 & 0:00:17 & 271 \\
\hline 13 & $\mathrm{x}$ & & $x$ & $x$ & & $x$ & $x$ & 3.06 & 0.72 & 3.22 & 0.72 & 3.29 & 0.72 & 0:00:05 & 79 \\
\hline 14 & & $x$ & $x$ & $x$ & & $x$ & $\mathrm{x}$ & 1.3 & 0.89 & 1.32 & 0.89 & 1.25 & 0.9 & 0:00:03 & 59 \\
\hline 15 & $x$ & $x$ & $x$ & & & $x$ & & 4.32 & 0.57 & 4.51 & 0.56 & 4.24 & 0.56 & 0:00:07 & 116 \\
\hline 16 & $x$ & $x$ & $x$ & & & & $x$ & 1.4 & 0.88 & 1.39 & 0.88 & 1.37 & 0.89 & 0:00:24 & 403 \\
\hline 17 & $x$ & $x$ & & & & $x$ & $x$ & 2.21 & 0.81 & 2.14 & 0.8 & 2.52 & 0.78 & 0:00:01 & 25 \\
\hline 18 & $x$ & & $x$ & & & $x$ & $x$ & 4.22 & 0.59 & 4.16 & 0.59 & 4.01 & 0.6 & 0:00:04 & 64 \\
\hline 19 & & $x$ & $x$ & & & $x$ & $x$ & 1.51 & 0.87 & 1.59 & 0.87 & 1.46 & 0.88 & 0:00:12 & 200 \\
\hline
\end{tabular}


Table 6. ANN Model 2 results with more than 10 neurons.

\begin{tabular}{|c|c|c|c|c|c|c|c|c|c|c|c|c|c|c|c|}
\hline \multirow[t]{2}{*}{ NET } & \multicolumn{7}{|c|}{ INPUTS } & \multicolumn{2}{|c|}{ TRAINING } & \multicolumn{2}{|c|}{ VALIDATION } & \multicolumn{2}{|c|}{ TESTING } & \multirow[b]{2}{*}{ Duration } & \multirow[b]{2}{*}{ Iterations } \\
\hline & Tpanel & Iglo & RH & Tamb & $\mathbf{P}$ & $\alpha$ & Isc & MSE & $\mathbf{R}$ & MSE & $\mathbf{R}$ & MSE & $\mathbf{R}$ & & \\
\hline 11 & $x$ & $x$ & $x$ & & & $x$ & $x$ & 1.22 & 0.9 & 1.22 & 0.9 & 1.27 & 0.9 & 0:00:10 & 158 \\
\hline $11 \_2$ & $x$ & $x$ & $x$ & & & $x$ & $x$ & 1.1 & 0.91 & 1.16 & 0.9 & 1.1 & 0.91 & $0: 00: 27$ & 234 \\
\hline 11_3 & $x$ & $x$ & $x$ & & & $x$ & $x$ & 1.16 & 0.9 & 1.32 & 0.89 & 1.25 & 0.9 & 0:00:28 & 136 \\
\hline 11_4 & $x$ & $x$ & $x$ & & & $x$ & $x$ & 1.01 & 0.92 & 1.01 & 0.91 & 0.96 & 0.92 & $0: 01: 25$ & 261 \\
\hline
\end{tabular}

In this scenario, the working mechanics are the same as in the previous one, adding one more possible entry. To find the variables, 19 tests were made, shown in Table 4, and divided into three blocks. The first block was comprised of network 1 to 8 , the second block from 9 to 14, and the third from 15 to the last test. In the first block, the pressure was again dispensed with, since in its absence, better results were obtained. In the second block, in addition to the pressure, the ambient temperature was eliminated, another of the stable variables, as it presented values higher than 0.9 in several of the training phases. Network 16 of the third block was the most suitable for this sector, presenting the smallest mean square errors and the regression coefficients closer to 1, eliminating solar altitude as an input variable. Comparing the three best grids in each block, it can be seen that the most suitable was grid 11 . They were better results with respect to grid 16 , and with respect to grid 4 there was no noticeable difference, reducing the iterations.

Once the input variables to the network were selected, the work was done with more than 10 neurons, reaching 40 although finally opting for 20 (Table 6). Working with 30 neurons resulted in a greater error, and the network of 40 neurons has no longer duration without a notorious improvement. Therefore, the selected network provided MSE values close to $1 \%$ and regression coefficients higher than 0.9 .

Figure 6 shows the initial network structure.

Inputs layer

Tpanel

Iglo

$\mathrm{RH}$

$\alpha$

Isc
Hidden layer

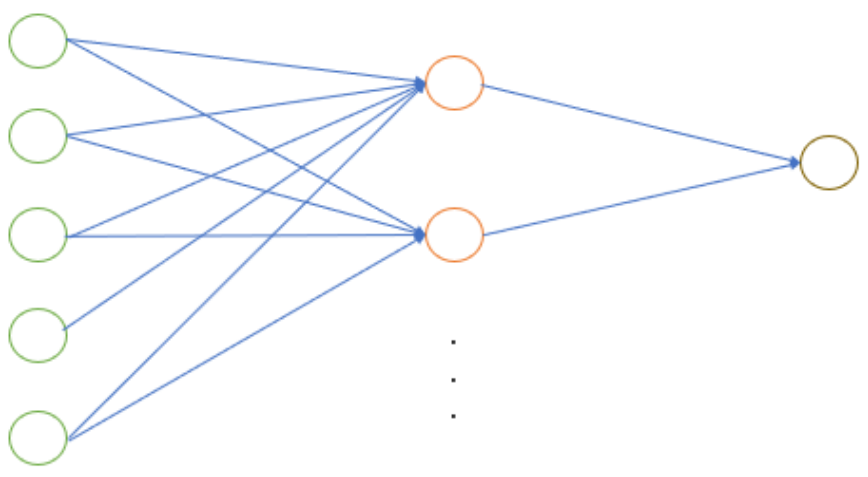

20 neurons

Soiling losses

Figure 6. Final Model 2 network.

Finally, the variables chosen for this Model 2 were the panel temperature, irradiance, relative humidity, solar altitude, and the short-circuit current.

\section{Results}

This section will show the final results for the models from the validation phase. In this phase, $20 \%$ of the total data was worked on. This percentage was chosen because the vast majority of the data must be invested in training, but it is necessary to leave a significant part for validation. For validation purposes, the real values were those obtained via the sensors and measurements made, whereas the estimates were those from the neural network models. To determine the success of the models, it was necessary to establish 
certain statistical indicators that prove the models' validity. For this, the statistical MBE, nMBE, RMSE, and nRMSE were used, in addition to the " $r$ " correlation coefficient.

Before studying the validation phase, Figure 7 shows the calculated losses (not estimated) from July to February.

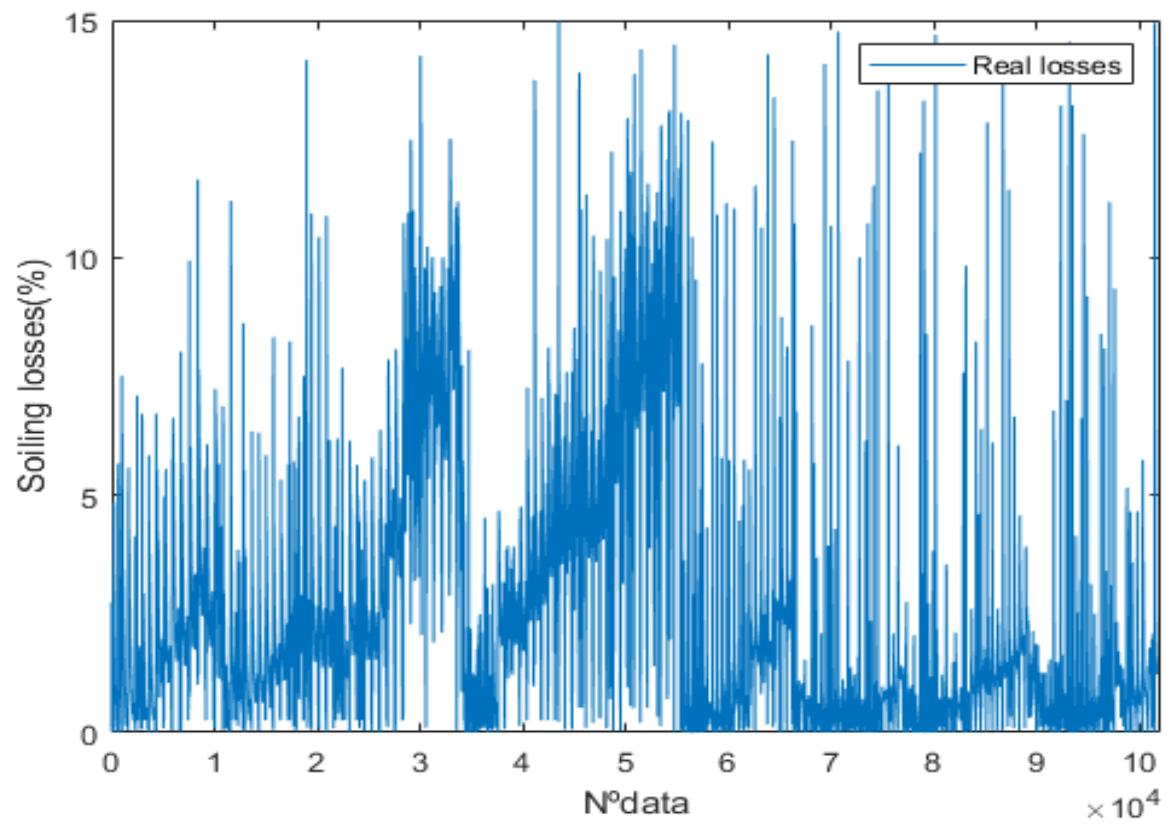

Figure 7. Real losses without Isc.

This graph shows the actual loss data as a whole. In other words, all the data, both from the training phase and the validation phase, are plotted. In this way, it was possible to study which has been the tendency of accumulation of soiling and the periods in which they suffered greater losses. The maximum values were in the range of $12 \%$ and $15 \%$ and an average of $2.3448 \%$.

\subsection{Model 1 Results}

This section presents the results obtained after modeling the soiling losses with ANN, but without including the short-circuit current of the unmaintained panel as an input variable. Figure 8 compares the real and estimated losses, and the data is in chronological order, so it is also possible to see how soiling has been accumulating from July to February.

The above graph shows how the soiling accumulated with upward trends as well as sudden drops; these were probably due to rain on both panels. To be clear, if both panels were totally clean, the losses caused by soiling would be 0 . In spite of the ups and downs and the great amplitude, in the middle of the graph, a very pronounced upward trend could be seen (possibly caused by episodes of Saharan soiling) and how, suddenly, the values fell back down, possibly due to rainfall. After that, a stable trend was maintained, synonymous with a soiling-free atmosphere. In this way, it was possible to perceive those periods during which there was more accumulated soiling, as well as the period in which it was the highest. Consequently, the modeling has proven satisfactory, even in the absence of the short-circuit current. Figure 9 shows a scatter plot where the real losses are represented against the estimated losses. 


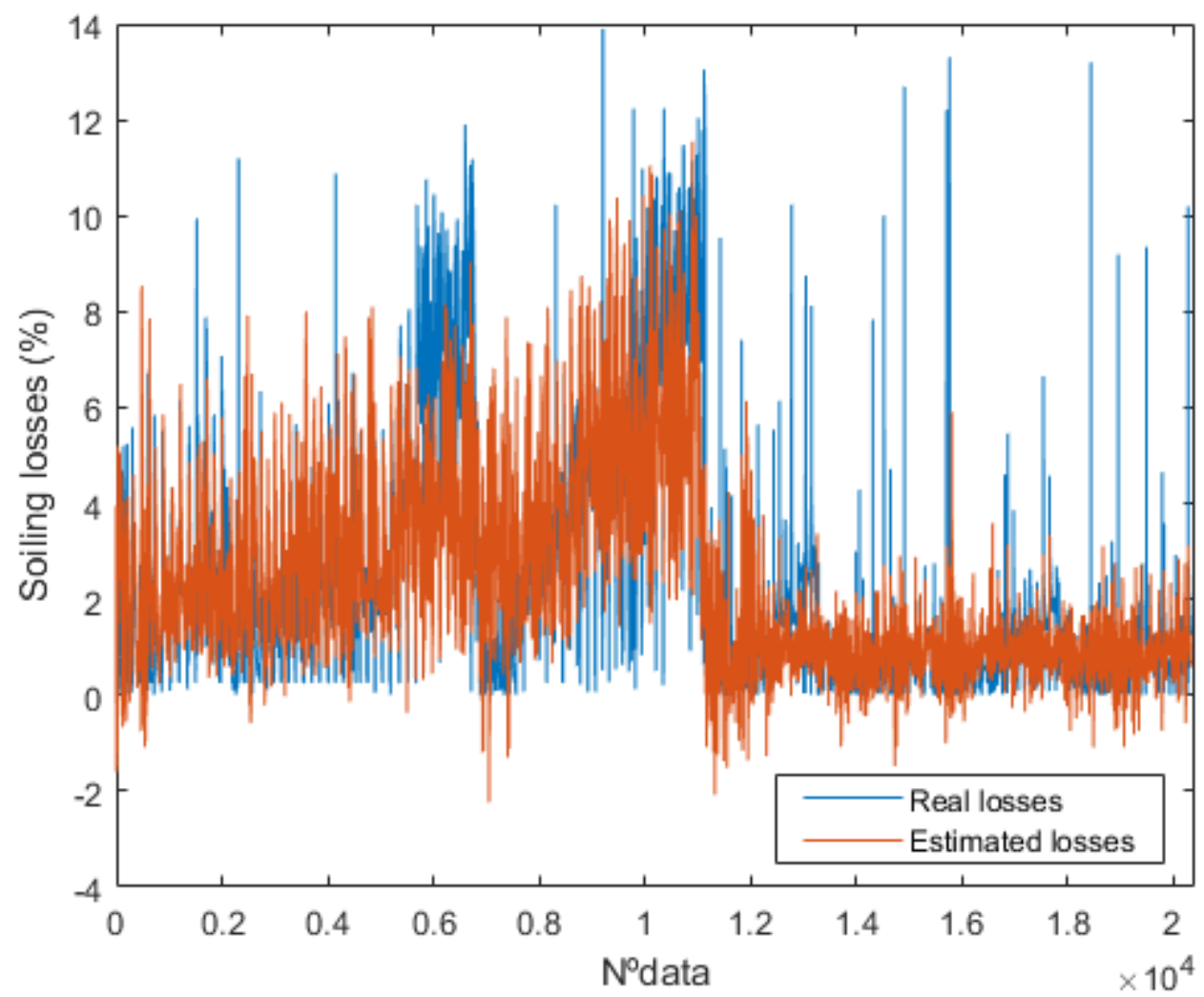

Figure 8. Comparison of real versus estimated losses without Isc.

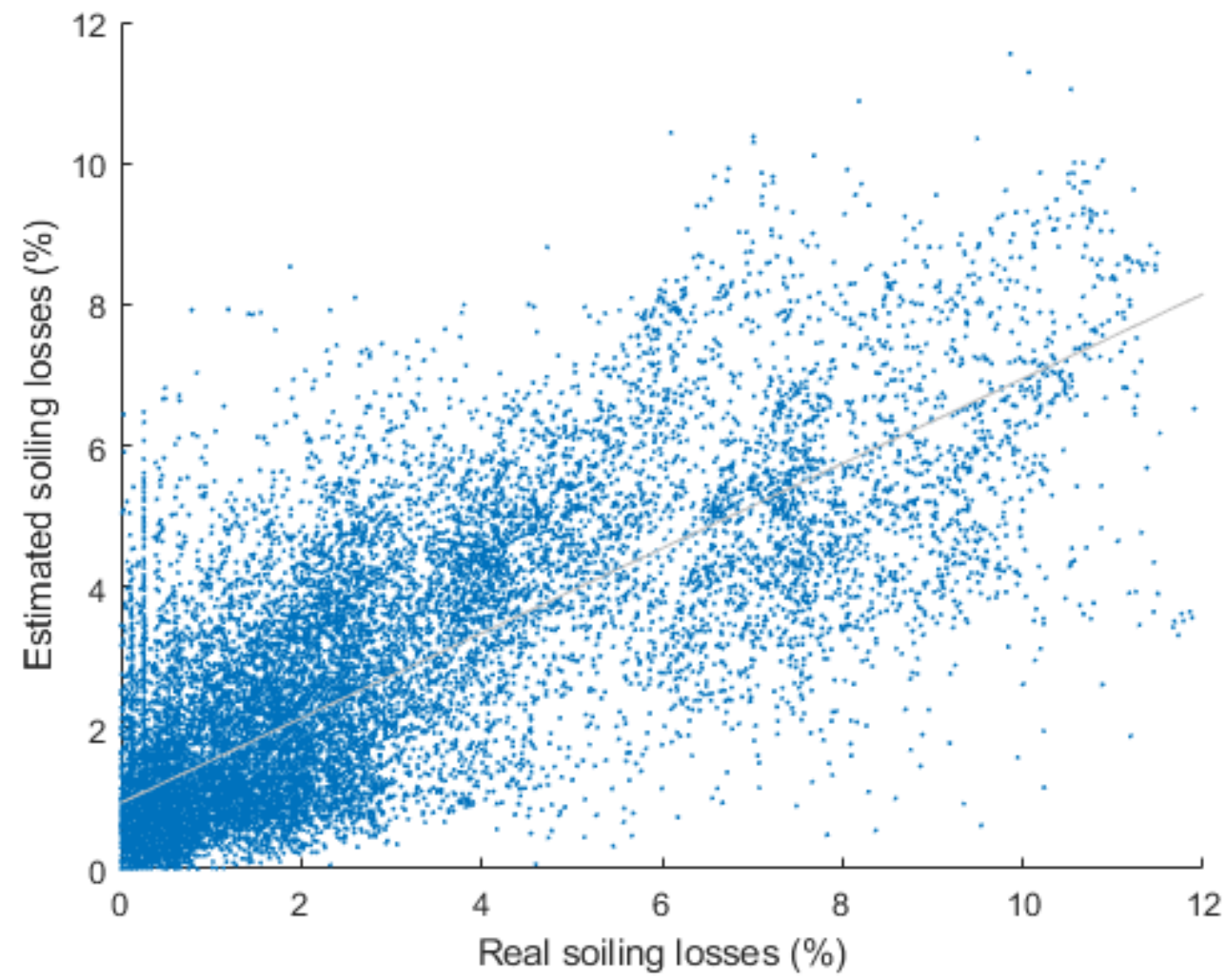

Figure 9. Scatter plot of actual vs. estimated losses without Isc.

Although not a perfect correlation, the two represented variables followed a positive linear trend. The point cloud follows this trend to a greater extent even if there are numer- 
ous points that move away from it, indicating a slight overestimation of the cases. The cloud is denser at the beginning, where most of the values are concentrated. This means that most losses were found in the range from $0 \%$ to $6 \%$, approximately, with the point cloud being diluted at higher values. Table 7 presents the parameters obtained from the network validation.

Table 7. Validation results of the soiling losses estimation without Isc.

\begin{tabular}{ccccc}
\hline MBE (\%) & nMBE (\%) & RMSE (\%) & nRMSE (\%) & r \\
\hline 0.00 & 0.03 & 1.60 & 11.60 & 0.77 \\
\hline
\end{tabular}

The table shows how the MBE and nMBE values determined that the model had not been overestimated, given that their values were close to zero. Likewise, the RMSE value and its normalization showed a $1.60 \%$ error in losses due to soiling, while the normalized error in percentage terms shows that it was below $12 \%$ for all the cases analyzed. Nevertheless, this standardized parameter was still within fairly acceptable limits since the estimate was considered good at between $10 \%$ and $20 \%$. The result of the " $r$ " correlation coefficient was very satisfactory, with a strong relationship between the two losses.

\subsection{Model 2 Results}

In the search for an optimal result to moderate these losses, the short-circuit current was incorporated into the neural network as a possible input variable. Figure 10 compares the actual and estimated soiling losses with ANN of a photovoltaic panel.

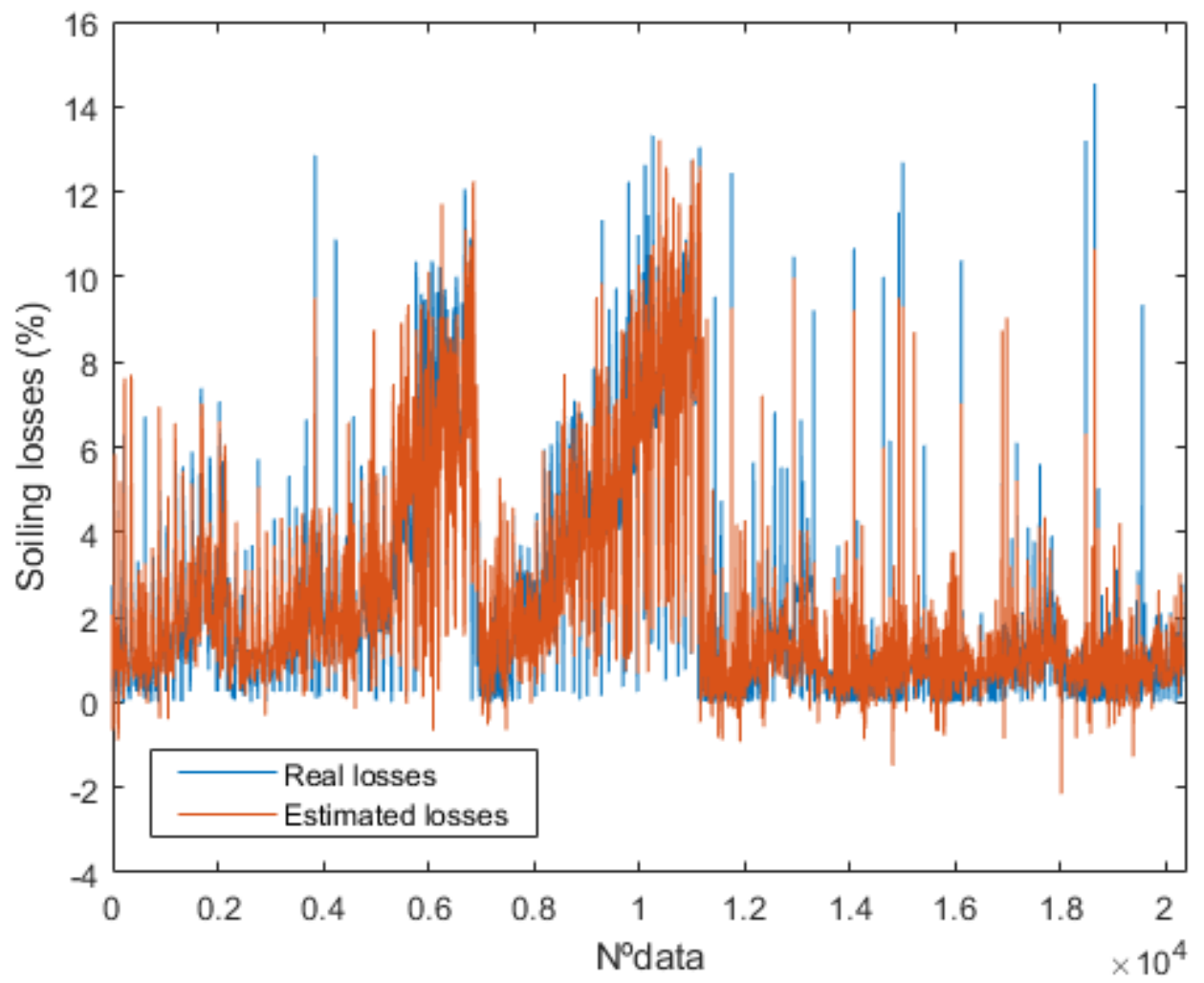

Figure 10. Comparison of real versus estimated losses of photovoltaic (PV) panels with Isc.

The graph shows how the network more efficiently estimated the losses by using the short-circuit current as an extra input. The settings were now finer, and a further adjustment of the soiling accumulation trends can be seen. The soiling accumulation overtime was still visible, with continuous rises and falls, as well as two large peaks in the middle of the graph. Therefore, during this period, the soiling accumulated to a greater 
extent than in previous scenarios, probably as a result of suspended soiling that had finally precipitated onto the panels. Figure 11 shows the scatter plot comparing the real losses and the estimated losses with ANN.

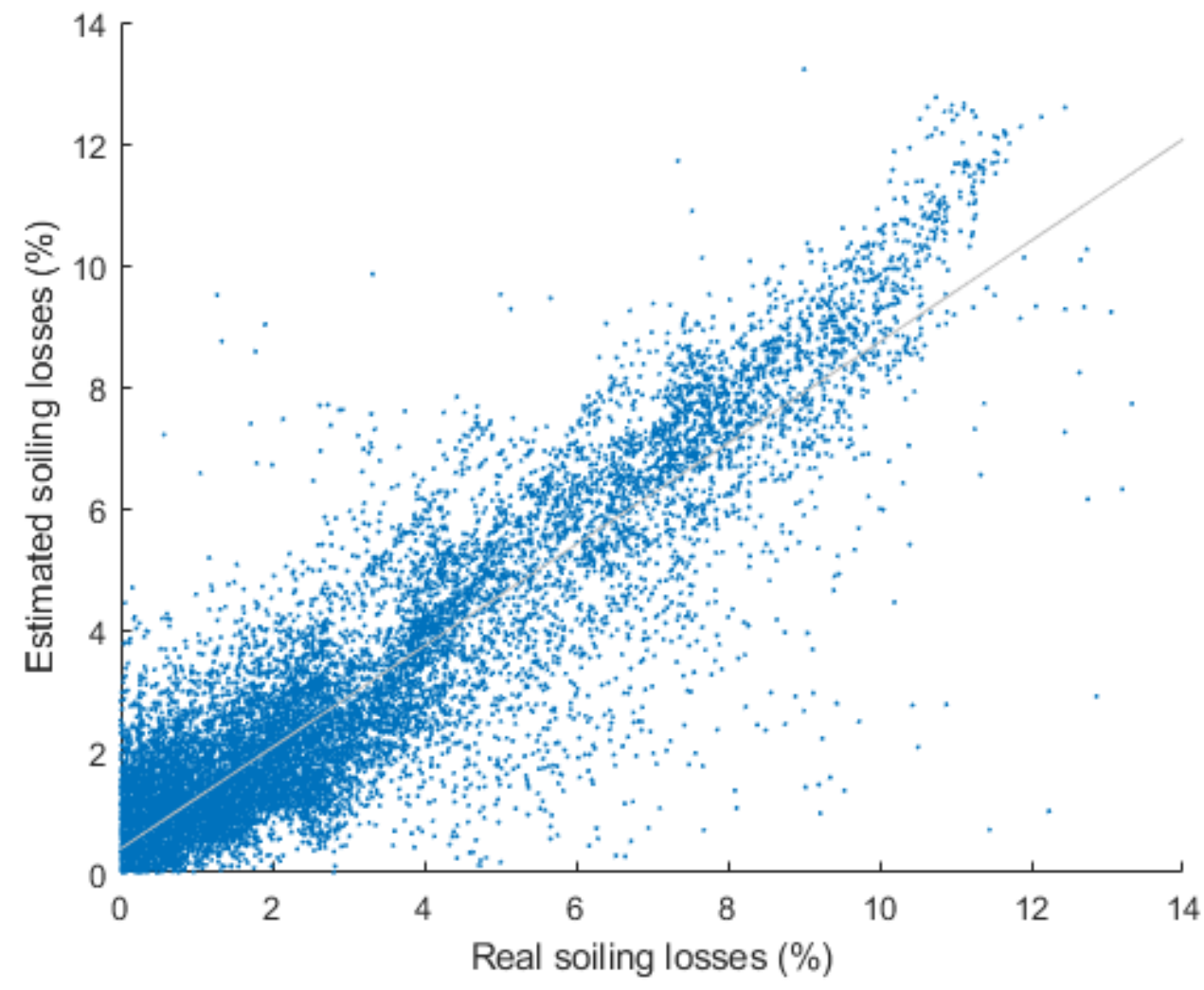

Figure 11. Scatter plot of actual vs. estimated losses with Isc.

This was a positive correlation because it was upward and linear, with most points following the same trend. The point cloud is denser in the first part, dispersing at the higher values, showing that the most common loss values are in the range between $0 \%$ and $6 \%$ losses. The important achievement of the model is that the point cloud is very homogeneous, with a clear linear trend (although some specific cases go beyond the fit line). Table 8 presents the parameters obtained in the network validation.

Table 8. Validation results of the soiling losses estimation with Isc.

\begin{tabular}{ccccc}
\hline MBE (\%) & nMBE (\%) & RMSE (\%) & nRMSE (\%) & r \\
\hline 0.01 & 0.03 & 1.04 & 6.79 & 0.91 \\
\hline
\end{tabular}

The table shows that the model was neither underestimated nor overestimated. One can also see a very significant improvement in the model error, given that the nRMSE, with a value of less than $7 \%$, signified a $5 \%$ improvement over the previous model. Therefore, one can conclude that the best model was that using the short-circuit current of the unmaintained panel to estimate the losses caused by soiling contamination. The " $\mathrm{r}$ " correlation coefficient shows a high positive dependence between the two variables, which was excellent.

Comparing with other models in the literature, (Laarabi et al., 2019) [32] used Iglo, wind speed and direction, Tamb, $\mathrm{RH}$, and rainfall to create a neural network and see the effect of soiling in Morocco, resulting in a neural network with a total of 35 hidden layers, where the RMSE was close to 0.5\%, the Mean Absolute Percentage Error (MAPE) greater than $9 \%$ and the higher r-value of 0.96 . In this sense, the model presented in this work 
needs two fewer variables (equivalent to a wind sensor), and the number of hidden neurons is reduced, making its execution more efficient and where the results are quite similar.

\section{Discussion}

The need to optimize photovoltaic plants makes soiling accumulation an important variable. It has been shown to have a significant effect on performance and to cause numerous losses; for this reason, it should not go undetected. Knowing these losses provides the opportunity to propose efficient maintenance without exhausting water or unnecessary resources since the final objective is to obtain the cleanest energy possible.

Performing maintenance on one panel but not another is a good way of comparing and studying any possible differences. This is what was done using an experimental photovoltaic plant located at CIESOL. Several sensors and various meteorological variables were measured in order to study their effect on soiling. In this work, only two panels were used to characterize dust losses. The panels had been positioned at $22^{\circ}$, oriented to the South.

Artificial neural networks were used to estimate the losses caused by soiling contamination on the photovoltaic panels. The correlation of all these variables was studied, and it was concluded that none of the variables had a strong correlation with the losses; thus, there was no linearity between the input and output variables. To construct the model, $80 \%$ of the data were used, while the remaining $20 \%$ were used for model validation.

The modeling was performed using artificial neural networks, studying which variables were the best as possible inputs, as well as finding out the number of neurons with which best results were obtained. In this context, two different scenarios were defined. In the first scenario, soiling losses were estimated using the module temperature, the irradiance on the array plane, the ambient temperature, and the solar altitude. The results obtained showed that the nMBE was close to $0 \%$ whereas the nRMSE was less than $12 \%$. In the case of the " $r$ " correlation coefficient, the value corresponded to 0.77 , which showed a strong correlation between the real and estimated losses.

In the second scenario, the same soiling loss was modeled based on the module temperature, the irradiance at the array plane, the relative humidity, the short circuit current, and the solar altitude. The results show a very significant improvement compared to the model without Isc, obtaining an nMBE of $0 \%$ and an nRMSE value of approximately $6.80 \%$. The " $r$ " correlation coefficient had a value higher than 0.90 , showing how successful the model is.

It could be said that for both networks, the input variables were the same, although they replaced the ambient temperature with the relative humidity in model 2 and add the short circuit current. Therefore, it is intuitive that the variables needed to estimate these losses are the temperature in the panel, the irradiance in the plane of the array, and the solar altitude, including the short circuit current in model 2 . The other variables are more stable and provide less information, and therefore they are more dispensable.

If two more modern panels are used, it is likely that the power will vary, even the Isc will surely vary, but the aim is to have the ratio between the clean and the dirty panel. Regardless of the values achieved, the ratio will give a value of difference and would be similar whatever the technology unless the panels used some antisoiling coating; but in this case, the price of PV panels cannot be compared with conventional PV panels.

Consequently, the novel technology presented in this work demonstrates that a satisfactory model has been developed to estimate the losses caused by soiling, a factor that is important and relevant in these systems.

As a suggestion for possible future work, a study could be carried out to relate the influence of solar altitude, or time of day, with soiling losses. Also, it is expected to be able to contemplate the degradation of the panels for future studies, as well as the possible extrapolation of the method to other plants and geographies. It is worth mentioning that it is highly desirable to find the correlation between the instantaneous losses and the power losses affecting an industrial plant. Furthermore, a novel approach would be to conduct a 
socio-economic study on the effect of soiling and the importance of cleaning photovoltaic solar systems in order to optimize the economic performance of these systems and make them more profitable.

Author Contributions: Conceptualization, J.A.-M.; methodology, N.S.P. and J.A.-M.; software, N.S.P.; validation, J.A.-M. and F.J.B.; formal analysis, J.A.-M.; investigation, N.S.P. and J.A.-M.; resources, J.A.-M.; data curation, N.S.P.; writing—original draft preparation, N.S.P. and J.A.-M.; writing—review and editing, N.S.P. and J.A.-M.; visualization, J.A.-M.; supervision, J.A.-M.; project administration, F.J.B.; funding acquisition, F.J.B. All authors have read and agreed to the published version of the manuscript.

Funding: This research was funded by the Spanish Ministry of the Economy, Industry, and Competitiveness, grant number ENE2017-83790-C3-1-2-3-R, in collaboration with the European Regional Development Fund.

Institutional Review Board Statement: Not applicable.

Informed Consent Statement: Not applicable.

Acknowledgments: In this section you can acknowledge any support given which is not covered by the author contribution or funding sections. This may include administrative and technical support, or donations in kind (e.g., materials used for experiments).

Conflicts of Interest: The authors declare no conflict of interest.

$\begin{array}{ll}\text { Abbreviations } & \\ \text { Nomenclature } & \text { Description } \\ \text { ANN } & \text { Artificial Neural Network } \\ \text { RH } & \text { Relative humidity } \\ \text { Isc } & \text { Short circuit current } \\ \text { Iglo } & \text { Global irradiance } \\ \text { MBE } & \text { Mean Bias Error } \\ \text { MSE } & \text { Mean Square Error } \\ \text { nMBE } & \text { normalized Mean Bias Error } \\ \text { nRMSE } & \text { normalized Root Mean Square Error } \\ \text { P } & \text { Atmospheric pressure } \\ \text { r } & \text { Correlation Coefficient } \\ \text { RMSE } & \text { Root Mean Square Error } \\ \text { Tamb } & \text { Ambient temperature } \\ \text { Tpanel } & \text { Panel temperature } \\ \alpha & \text { Solar altitude }\end{array}$

\section{References}

1. Diaf, S.; Diaf, D.; Belhamel, M.; Haddadi, M.; Louche, A. A methodology for optimal sizing of autonomous hybrid PV/wind system to cite this version. Energy Policy 2007, 35, 5708-5718. [CrossRef]

2. Chen, B.; Lin, P.; Yunfeng, L.; Cheng, S.; Chen, Z.; Wu, L. Very-Short-Term Power Prediction for PV Power Plants Using a Simple and Effective RCC-LSTM Model Based on Short Term Multivariate Historical Datasets. Electronics 2020, 9, 289. [CrossRef]

3. Mohtasham, J. Review Article—Renewable Energies. Energy Procedia 2015, 74, 1289-1297. [CrossRef]

4. Kabir, E.; Kumar, P.; Kumar, S.; Adelodun, A.A.; Kim, K.-H. Solar energy: Potential and future prospects. Renew. Sustain. Energy Rev. 2018, 82, 894-900. [CrossRef]

5. Gabaldón-Estevan, D.; Peñalvo-López, E.; Alfonso-Solar, D. The Spanish Turn against Renewable Energy Development. Sustainanility 2018, 10, 1208. [CrossRef]

6. Mustafa, R.J.; Gomaa, M.R.; Al-Dhaifallah, M.; Rezk, H. Environmental Impacts on the Performance of Solar Photovoltaic Systems. Sustainability 2020, 12, 608. [CrossRef]

7. Massucco, S.; Mosaico, G.; Saviozzi, M.; Silvestro, F. A Hybrid Technique for Day-Ahead PV Generation Forecasting Using Clear-Sky Models or Ensemble of Artificial Neural Networks According to a Decision Tree Approach. Energies 2019, $12,1298$. [CrossRef]

8. Martynov, A.; Sushama, L.; Laprise, R. Simulation of temperate freezing lakes by one-dimensional lake models: Performance assessment for interactive coupling with regional climate models. Boreal Environ. Res. 2010, 15, 143-164. [CrossRef] 
9. Al-Kouz, W.; Al-Dahidi, S.; Hammad, B.; Al-Abed, M.A. Modeling and Analysis Framework for Investigating the Impact of Dust and Temperature on PV Systems' Performance and Optimum Cleaning Frequency. Appl. Sci. 2019, 9, 1397. [CrossRef]

10. Willoughby, A.A.; Osinowo, M.O. Development of an electronic load I-V curve tracer to investigate the impact of Harmattan aerosol loading on PV module pern2tkformance in southwest Nigeria. Sol. Energy 2018, 166, 171-180. [CrossRef]

11. Abd-Elhady, M.; Zayed, S.I.M.; Rindt, C.C.M. Removal of dust particles from the surface of solar cells and solar collectors using surfactants. In Proceedings of the International Conference on Heat Exchanger Fouling and Cleaning, Crete Island, Greece, 5-10 June 2011; Volume 2011, pp. 342-348.

12. Costa, S.C.; Diniz, A.S.A.; Kazmerski, L.L. Solar energy dust and soiling R\&D progress: Literature review update for 2016. Renew. Sustain. Energy Rev. 2018, 82, 2504-2536. [CrossRef]

13. Maghami, M.R.; Hizam, H.; Gomes, C.; Radzi, M.A.; Rezadad, M.I.; Hajighorbani, S. Power loss due to soiling on solar panel: A review. Renew. Sustain. Energy Rev. 2016, 59, 1307-1316. [CrossRef]

14. Semaoui, S.; Arab, A.H.; Boudjelthia, E.K.; Bacha, S.; Zeraia, H. Dust Effect on Optical Transmittance of Photovoltaic Module Glazing in a Desert Region. Energy Procedia 2015, 74, 1347-1357. [CrossRef]

15. Martín, N.; Chenlo, F.; Alonso-García, M.C.; Ariza, M.A.; Mejuto, E.; Angulo, M. Surface Soiling Losses Measurement in PV Modules Under Real Operation. In Proceedings of the 26th European Photovoltaic Solar Energy Conference and Exhibition, Hamburg, Germany, 5-9 September 2011; pp. 3597-3599.

16. Alquthami, T.S.; Menoufi, K. Soiling of Photovoltaic Modules: Comparing between Two Distinct Locations within the Framework of Developing the Photovoltaic Soiling Index (PVSI). Sustainability 2019, 11, 4697. [CrossRef]

17. Syafiq, A.; Pandey, A.; Adzman, N.; Rahim, N.A. Advances in approaches and methods for self-cleaning of solar photovoltaic panels. Sol. Energy 2018, 162, 597-619. [CrossRef]

18. Martín-Chivelet, N.; Polo, J.; Alonso, M.; Sanz, C.; Batlles, F.J.; Alonso-Montesinos, J.; Bosch, J.L.; Barbero, J. Characterization and modeling of the soiling effect on the PV generation under urban Mediterranean conditions. In Proceedings of the 36th European Photovoltaic Solar Energy Conference and Exhibition (EU PVSEC 2019), Marseille, France, 9-13 September 2019.

19. Zhang, X.; Zhao, L.; Tong, D.Q.; Wu, G.; Dan, M.; Teng, B. A Systematic Review of Global Desert Dust and Associated Human Health Effects. Atmosphere 2016, 7, 158. [CrossRef]

20. Sabatier, P.; Nicolle, M.; Piot, C.; Colin, C.; Debret, M.; Swingedouw, D.; Perrette, Y.; Bellingery, M.-C.; Chazeau, B.; Develle, A.-L.; et al. Past African dust inputs in the western Mediterranean area controlled by the complex interaction between the Intertropical Convergence Zone, the North Atlantic Oscillation, and total solar irradiance. Clim. Past 2020, 16, 283-298. [CrossRef]

21. Soupiona, O.; Papayannis, A.; Kokkalis, P.; Foskinos, R.; Sánchez Hernández, G.; Ortiz-Amezcua, P.; Mylonaki, M.; Papanikolaou, C.-A.; Papagiannopoulos, N.; Samaras, S. Saharan dust intrusions over the northern Mediterranean region in the frame of EARLINET (2014-2017): Properties and impact in radiative forcing. Atmos. Chem. Phys. 2020, 20, 15147-15166. [CrossRef]

22. Ferrada, P.; Olivares, D.; del Campo, V.; Marzo, A.; Araya, F.; Cabrera, E.; Llanos, J.; Correa-Puerta, J.; Portillo, C.; Román Silva, D.; et al. Physicochemical characte-rization of soiling from photovoltaic facilities in arid locations in the Atacama Desert. Sol. Energy 2019, 187, 47-56. [CrossRef]

23. Rao, A.; Pillai, R.; Mani, M.; Ramamurthy, P.C. Influence of Dust Deposition on Photovoltaic Panel Performance. Energy Procedia 2014, 54, 690-700. [CrossRef]

24. Zorrilla-Casanova, J.; Philiougine, M.; Carretero, J.; Bernaola, P.; Carpena, P.; Mora-López, L.; Sidrach-De-Cardona, M. Analysis of Dust Losses in Photovoltaic Modules. In Proceedings of the World Renewable Energy Congress, Linköping, Sweden, 8-13 May 2011; Volume 57, pp. 2985-2992. [CrossRef]

25. Reguera Gil, F.J. Análisis de la Degradación de Módulos Fotovoltaicos. Ph.D. Thesis, Universidad Internacional de Andalucía, Sevilla, Spain, 2015.

26. Hudedmani, M.G.; Joshi, G.; Umayal, R.M.; Revankar, A. A Comparative Study of Dust Cleaning Methods for the Solar PV Panels. Adv. J. Grad. Res. 2017, 1, 24-29. [CrossRef]

27. You, S.; Lim, Y.J.; Dai, Y.; Wang, C.-H. On the temporal modelling of solar photovoltaic soiling: Energy and economic impacts in seven cities. Appl. Energy 2018, 228, 1136-1146. [CrossRef]

28. Polo, J.; Martín-Chivelet, N.; Alonso, M.; Sanz, C.; Batlles, F.J.; López, G.; Zitouni, H.; Alonso-Montesinos, J.; Vela-Barrionuevo, N.; Bosch, J.L.; et al. Characterization of PV Soiling Losses in Urban Mediterranean Environment. In Proceedings of the ISES Solar World Congress, Santiago, Chile, 4-7 November 2019; pp. 756-763. [CrossRef]

29. Zhong, J.; Liu, L.; Sun, Q.; Wang, X. Prediction of Photovoltaic Power Generation Based on General Regression and Back Propagation Neural Network. Energy Procedia 2018, 152, 1224-1229. [CrossRef]

30. Rosiek, S.; Alonso-Montesinos, J.; Batlles, F. Online 3-h forecasting of the power output from a BIPV system using satellite observations and ANN. Int. J. Electr. Power Energy Syst. 2018, 99, 261-272. [CrossRef]

31. Demuth, H. Neural Network Toolbox Documentation. For Use with MATLAB; The MathWorks, Inc.: Natick, MA, USA, $2004 ;$ p. 846.

32. Laarabi, B.; Tzuc, O.M.; Dahlioui, D.; Bassam, A.; Flota-Bañuelos, M.; Barhdadi, A. Artificial neural network modeling and sensitivity analysis for soiling effects on photovoltaic panels in Morocco. Superlattices Microstruct. 2019, 127, 139-150. [CrossRef] 